\title{
MOTIFS: a monitoring tool for integrated farm sustainability
}

\author{
Marijke Meul ${ }^{1,2 *}$, Steven VAn PASSEL ${ }^{3}$, Frank NeVEns ${ }^{4}$, Joost Dessein ${ }^{1}$, Elke RogGE $^{1}$, Annelies MulieR $^{5}$, \\ Annelies VAN HAUWERMEIREN ${ }^{6}$ \\ ${ }^{1}$ Institute for Agricultural and Fisheries Research, Social Sciences Unit, Burg. van Gansberghelaan 109 box 2, 9820 Merelbeke, Belgium \\ ${ }^{2}$ Ghent University, Faculty of Bioscience Engineering, Coupure Links 653, 9000 Ghent, Belgium \\ ${ }^{3}$ Hasselt University, Faculty of Applied Economics, Centre for Environmental Sciences, Agoralaan Building D (C57), 3590 Diepenbeek, Belgium \\ ${ }^{4}$ Vlerick Leuven Gent Management School, Reep 1, 9000 Ghent, Belgium \\ ${ }^{5}$ Kokerstraat 24, 8750 Wingene, Belgium \\ ${ }^{6}$ Vlaamse Landmaatschappij, Cardijnlaan 1, 2200 Herentals, Belgium
}

(Accepted 2 January 2008)

\begin{abstract}
Indicator-based monitoring tools are frequently applied for sustainability assessments, also in agriculture. However, many indicators focus on a rather restricted number of sustainability aspects such as economy or ecology. Moreover the choice of the indicator is rarely explained. The aim of our study was to develop an indicator-based monitoring tool for integrated farm sustainability - i.e. taking into account economic and ecological and social aspects - based on a supported vision of sustainable agriculture and using a set of relevant indicators. Hereby, specific attention was paid to aspects of communication and user-friendliness. Four methodological steps were considered: (i) translating the major principles of a supported vision of sustainable Flemish agriculture into concrete and relevant themes; (ii) designing indicators to monitor progress towards sustainability for each of those themes; (iii) aggregating the indicators into an integrated farm sustainability monitoring tool and (iv) applying the monitoring tool on a practical farm, as a first attempt at end-use validation. Stakeholder participation and expert consulting played an important part in each of these methodological steps. As a case study, the methodology was applied to Flemish dairy farms. As a result, we developed MOTIFS, a user-friendly and strongly communicative indicator-based monitoring tool that allows the measurement of progress towards integrated sustainable dairy farming systems and fits within a well-founded methodological framework. MOTIFS is based on the equality of the economic, ecological and social sustainability dimensions, and this equality is inherently built into the system. Through the applied methodology, we founded the selected themes and indicators and we avoided using indicators that are not relevant to the problem at hand.
\end{abstract}

aggregation / dairy farms / indicators / integrated sustainability / monitoring / flanders

\section{INTRODUCTION}

'Sustainable development is development that meets the needs of the present without compromising the ability of future generations to meet their own needs' (WCED, 1987). This 'Brundtland-definition' is known worldwide, and has rightfully gained its place in the vision, mission and strategy of companies, organizations and governments. However, putting the theoretical concept into practice, into actual measures and actions, often proves to be very difficult - also in agriculture. A useful tool to effectively solve this 'sustainability paradox' between theory and practice is a framework that considers sustainable development as a long-term, complex and drastic process of change (a 'transition'; Rotmans, 2003; Geels, 2005). This framework consists of four actions: (i) developing a vision, (ii) establishing one or more strategies, (iii) taking action

\footnotetext{
* Corresponding author: marijke.meul@ilvo.vlaanderen.be, marijke.meul@gmail.com
}

and (iv) monitoring progress. A vision describes images of an envisioned, sustainable future. Strategies align possible paths from the current situation towards the envisioned future and serve as a decision-base for taking actions. Finally, a monitoring instrument, e.g. a set of indicators or a model, is used to follow up whether running or anticipated actions actually contribute to achieving the objectives defined by the vision. The aim of the present work fits into this final step of the sketched process: developing a monitoring tool, in our case specifically designed to effectively advise Flemish farmers on several aspects of farm sustainability, and hence to guide them towards more sustainable ways of agricultural production.

Indicators are often used in sustainability monitoring (Bell and Morse, 1999). For agriculture, indicator-based farm monitoring tools already exist and are applied in practice. In such tools, indicators are used (i) individually, (ii) as part of a set, or (iii) combined into a composite index (Farrell and Hart, 1998). Since individual indicators are of limited use to 
adequately represent all essential aspects of a complex system's viability and sustainability, a balanced set of indicators is preferred (Bossel, 1999). Hereby, a graphical presentation of multiple indicator scores is often used, allowing a comprehensive overview and mutual comparison of the indicators for different sustainability aspects. Examples of such a 'visual integration' are radar graphs (Gomez et al., 1996; Bockstaller et al., 1997; Rigby et al., 2001) or bar graphs (Lewis and Bardon, 1998). Graphic methods can be used as decision-aid tools, to measure and compare farm progress towards a more sustainable agriculture and they are considered well-suited for effective communication about sustainability. Aggregating indicator values into a single composite index ('numerical integration', e.g. Taylor et al., 1993) has been found particularly useful to compare policy options and to inform the public and decision-makers on the sustainability of a system (Farrell and Hart, 1998). This method summarizes complex or multi-dimensional issues and provides the big picture, without the danger of information overload (Jollands et al., 2004). However, the lack of transparency of highly aggregated indices can be a serious problem (Bell and Morse, 2003), possibly leading to misinterpretations. A somewhat particular method of numerical integration is the Sustainable Value Added (SVA) approach (Figge and Hahn, 2004; Van Passel et al., 2007), in which the single composite index is expressed in monetary terms. It is obvious that both method types - visual and numerical integration - can be combined (e.g. Girardin et al., 2000).

An overview of existing monitoring tools used in agriculture shows that many of them focus on a rather restricted number of sustainability aspects, in general economic and/or ecological (von Wirén-Lehr, 2001). Such tools cannot be used to genuinely evaluate a farm's integrated sustainability, i.e. taking into account economic and ecological as well as social aspects. Another striking observation is that only a few authors explain how and why the considered sustainability aspects and indicators were selected (van der Werf and Petit, 2002).

The aim of our study was to develop an indicator-based monitoring tool for integrated farm sustainability, that is based on a supported vision of sustainable agriculture and uses a set of relevant indicators. Since we envision that the developed monitoring tool will be used in practice as a management guiding tool, we paid specific attention to aspects of communication and user-friendliness. In this article, we describe the applied methodology for developing this monitoring tool and we illustrate its practical use on a Flemish dairy farm as a case study. We considered four successive steps:

- translation of the major principles of a supported vision of sustainable Flemish agriculture into concrete and relevant themes for individual farms;

- design of indicators to monitor progress towards sustainability for each of those themes;

- aggregation of the indicators into an integrated farm sustainability monitoring tool;

- application of the monitoring tool on a practical farm, as a first attempt of end-use validation.

\section{MATERIALS AND METHODS}

\subsection{Translating a vision into concrete and relevant themes}

Sustainable development processes should be based on a well-conceived vision, with concrete and inspiring images of an envisioned future (Hardi and Zdan, 1997). Nevens et al. $(2005,2007)$ describe a process of vision development on a sustainable (future of) agriculture in Flanders. This process was based on a transdisciplinary dialogue between the many stakeholders of Flemish agriculture. We considered the resulting vision - 'On tomorrow's grounds' - as a publicly supported guideline for all actors including farmers, agricultural industry, consumers and government. It integrates major principles for the ecological, the economic and the social sustainability dimensions of agricultural systems. In mutual agreement with stakeholders, we translated those major principles into concrete themes to make 'sustainability' more tangible at a practical level, to be able to take directed actions and to design relevant indicators.

\subsection{Designing indicators}

To further concretize the selected sustainability themes, we designed relevant indicators.

\subsubsection{Indicator criteria}

According to the International Institute for Sustainable Development (Bossel, 1999), an indicator quantifies and simplifies phenomena and complex realities into a manageable amount of meaningful information, feeding decisions and directing actions. In other words, in the present study the indicators should give a clear signal for appropriate action and hence guide farmers' management towards a higher level of sustainability. Considering their effectiveness, we imposed a number of criteria for the indicators:

- there is an obvious and well-defined relationship between an indicator and the phenomenon to monitor (causality);

- a change in the situation is reflected in a value change of the indicator (sensitivity);

- the well-documented calculation method of the indicator value minimally depends on external factors (solidness);

- benchmarks are available to evaluate the indicator value (use of benchmarks);

- indicator values and scores are easily interpretable (comprehensibility).

\subsubsection{Indicator selection and design}

Extensive literature is available on the development and use of indicators to measure farm sustainability. In a majority of cases, they address ecological and/or economic aspects. Whenever such existing indicators complied with our 
supported vision, the derived themes and the imposed quality criteria, we integrated them into our monitoring tool. When little or no scientific information was available - which was particularly the case for the social themes - we consulted stakeholders (including experts) to select or design relevant indicators, again taking into account the pre-defined quality criteria. This approach of consulting stakeholders and experts to assess the relevant indicators of ecological, economic and social sustainability was also successfully applied by van Calker et al. (2005). For some social aspects of sustainable farming, neither scientific information nor expert knowledge was available. In these cases, we performed new fundamental research (e.g. Dessein and Nevens, 2007).

\subsubsection{Data availability}

Since we envision that the monitoring tool will be used in practice to guide farmers' actions, practical applicability is a major concern. Therefore, to calculate indicator values, we maximally used data that are readily available on farms, or that entail minimum extra costs and/or efforts to collect. Some indicators require quantitative farm data, e.g. amounts of inputs used, amounts of produced products, soil organic matter content, while others are based on qualitative data, e.g. from questionnaires or checklists.

\subsubsection{Indicator scores}

For each of the selected indicators, we defined minimum $\left(\mathrm{B}_{\min }\right)$ and maximum $\left(\mathrm{B}_{\max }\right)$ benchmarks, enabling us to rescale indicator values into scores between 0 , indicating a worst-case situation, and 100, indicating assumed sustainability. This rescaling allows for a mutual comparison of indicators for different aspects of sustainability. We applied several approaches to define benchmark values:

- Scientific knowledge and/or legislative standards: e.g. a farm 'nitrogen $(\mathrm{N})$-surplus' of $150 \mathrm{~kg} \mathrm{ha}^{-1}\left(\mathrm{~B}_{\max }\right)$ or less is compliant with the European Nitrates Directive on soil water protection (Nevens et al., 2006).

- The indicator values of a reference group of comparable farms: the $10 \%$ best-performing farms (pragmatic choice) delimit the 100 score $\left(\mathrm{B}_{\max }\right)$, the $10 \%$ lowest-performing farms the 0 score $\left(\mathrm{B}_{\mathrm{min}}\right)$. Intermediate indicator values are transferred into linearly intermediate scores. In this study, we used dairy farm data of the Flemish Farm Accountancy Data Network (FADN) as a reference group. The FADN is a database of technical and economic data from a representative set of Flemish farms.

- A production possibility curve: this curve represents the maximum attainable productivity of a farm (Van Passel et al., 2006). E.g., the score of the indicator 'technical efficiency' equals the ratio (in \%) between the farm's actual productivity and the maximum attainable productivity $\left(\mathrm{B}_{\max }\right)$.
- Best available techniques: the indicator score is defined by the share of techniques of e.g. pesticide or wastewater management that are actually applied on the farm, compared with the maximum package of combinable alternatives of best available techniques $\left(\mathrm{B}_{\max }\right)$.

- The results of a questionnaire: we applied this method mainly for subjective assessment of social indicators such as 'professional pride', for which a farmer himself determines the score on a scale between $0\left(B_{\min }\right)$ and $100\left(\mathrm{~B}_{\max }\right)$.

- Expert judgement: we applied this method when none of the other approaches was suitable for defining benchmarks, e.g. in the cases of 'landscape management' and 'entrepreneurship'. Based on the farmers' answers to a number of relevant questions, experts placed the farms for the specific theme in a progressive $\left(\mathrm{B}_{\max }\right)$, an average or an end group $\left(\mathrm{B}_{\min }\right)$ with related scores.

\subsubsection{Indicator weights}

Weighting single indicators for aggregation is often dependent on subjective scoring (von Wirén-Lehr, 2001), and this is also the case in our study. We weighted the indicators according to the assumption that all selected sustainability themes are equally important. This rule takes into account the equality of the economic, ecological and social pillars. Within a specific theme, we considered all indicators as equally important and consequently assigned them an equal weight, except when based on expert opinions or on literature reviews - there was considerable proof that certain indicators are in fact more important than others when used to evaluate the sustainability of the specific theme. This was specifically the case for the indicators designed to evaluate a farm's (economic) 'productivity' and for 'soil quality'.

\subsubsection{Indicator validation}

Despite the extended interest in and literature on indicator development, relatively little is known in terms of validation processes (Rigby et al., 2001). Bockstaller and Girardin (2003) proposed a methodological framework for indicator validation, considering the following definition: "an indicator is validated if it is well founded and if it achieves the overall objectives or produces the intended effects". The first part of the definition relates to the scientific quality of the construction or design of the indicator, referred to as 'design validation'. The second part checks whether the indicators actually achieve the objectives for which they are designed: taking into account the indicator objectives defined by Bossel (1999) mentioned above, this includes an evaluation of the information that is supplied by the indicator output - referred to as 'output validation' (Bockstaller and Girardin, 2003) - and an evaluation of the usefulness of the indicator for potential users to make decisions - referred to as 'end-use validation'.

Building on this framework, Cloquell-Ballester et al. (2006) proposed a method for validating environmental and social 
indicators, considering three stages: a self-validation stage carried out by the 'working team' itself to reflect on the correct performance and assure the correct documentation of indicators; a scientific validation stage, integrating independent experts' judgements; and a social validation stage, integrating stakeholders' opinions.

We combined the methodological principles proposed by Bockstaller and Girardin (2003) and Cloquell-Ballester et al. (2006) and used a transdisciplinary approach of expert and stakeholder participation (Thompson Klein et al., 2001; Astleithner and Hamedinger, 2003) to carry out the design and output validation of the indicators: we presented each indicator to a feedback group of experts and stakeholders to discuss the indicators' (perceived) relevance and underlying methodological choices such as indicator design, data use, benchmarks and indicator weights. As a first attempt at end-use validation, we applied the indicators to a Flemish dairy farm in practice, to evaluate their usefulness for potential end-users to make decisions. We acknowledge that a more elaborate validation procedure should be developed and applied to genuinely validate the sustainability indicators.

\subsection{Aggregating indicators into an integrated farm sustainability monitoring system}

Since the aim of our tool is to effectively communicate to farmers and advise them on several aspects of farm sustainability, we chose to aggregate the indicators in a graphical way, where all relevant themes are presented individually, instead of combined into a single aggregated index. We used a multi-level approach to aggregate the indicators: at the lowest level (level 3), the individual indicator scores for each selected sustainability theme are visually aggregated in a graph. At level 2, three graphs give an overview of the sustainability themes within each sustainability dimension: economic, ecological or social. Hereby, each theme's score is calculated as a weighted average of its individual indicator scores. Finally, a level 1 graph gives an overview of the farm's overall sustainability, aggregating all selected sustainability themes in one graph. This multi-level tool allows farmers to start from an overall view of the farm's sustainability (level 1), and zoom in on the underlying themes and indicators in as much detail as desired.

We further focused on a user-friendly and communicative design of the tool by:

- providing the ability to add the average indicator scores of a group of comparable farms. This option is particularly useful for farmers who wish to communicate about their farm sustainability in a discussion group;

- visualizing the indicator weights. That way, a farmer can readily distinguish which indicators are considered more or less important when evaluating the sustainability of a specific theme.

\subsection{Case study: sustainability monitoring at a Flemish dairy farm}

In this final step, we applied the monitoring tool to a practical farm, as a first attempt at end-use validation. The described methodological frame of vision development, defining relevant themes and constructing appropriate indicators, applies to all farm types and agricultural sectors. However, the final results, the selected themes and indicators, will be farm- or sector-specific. For example, a specialized arable farm will not need indicators to evaluate animal health and welfare, since this is not a relevant theme for this specific sector. In this study, we therefore applied the methodology specifically to the dairy sector as an example and we used the monitoring instrument on a specific dairy farm as a case study. This 38-ha farm (of which 17 ha is grassland and 18 ha maize) milks a quotum of 593000 liters with 70 Holstein milking cows. The farmer works full-time at the farm and his mother half-time (resulting in 1.5 labor units); his wife works off-farm. According to Flemish standards, this is a fairly large dairy farm.

\section{RESULTS AND DISCUSSION}

\subsection{Translating a vision into concrete and relevant themes}

The major principles underpinning a supported vision on sustainable agriculture in Flanders can be summarized as follows (Nevens et al., 2005, 2007).

From an ecological viewpoint, a sustainable agricultural system:

- functions within a stable agro-ecosystem, which can be ensured by (i) optimizing the preconditions for production, i.e. optimizing the quality of natural resources (air, soil, water); (ii) maximally closing physical and biological cycles; and (iii) preserving a broad ecological base, i.e. maximally maintaining and using biodiversity;

- works at the highest levels of eco-efficiency. According to the principle 'produce more from less', this means that it adds maximum value with minimum use of resources and/or with minimum environmental impact (WBCSD, 2000; Jollands et al., 2004);

- maximizes its positive impacts on the environment, e.g. by green services (biodiversity, nature) and blue services (water management).

From an economic angle, a sustainable agricultural system:

- maximizes its produced value-added products. The value added should be at least sufficient to remunerate the farm's production factors, e.g. farm labor, capital and land, at a level that is comparable with other economic sectors;

- uses the production factors in the most productive (value added / unit of production factor) and efficient (actual productivity / maximum attainable productivity) way; 
- minimizes the risk of farming activities; i.e. the production of value-added products is minimally impacted by external events, e.g. a change in interest rates or a sharp fall in price of agricultural commodities.

From a social viewpoint, sustainability is conceptualized in three dimensions:

- social inclusion (Cousins, 1999), encompassing a sufficient level of access of farmers to provisions such as housing, income, health, labor and good working conditions, services, facilities, education and financial security;

- identity, enabling a farmer to live according to his/her own values and norms, within the limits of pre-conditions postulated by the larger society;

- social capital, referring to the diverse networks and relations of trust between people involved in agriculture. Social capital strengthens social cohesion and stability within groups of people, organizations or society at large. Hence, it eventually creates a broad social support base for agriculture.

We translated these major principles into 10 relevant themes for sustainable agricultural production:

- (1) use of inputs, (2) quality of natural resources and (3) biodiversity, referring to ecological sustainability;

- (4) profitability, (5) productivity and efficiency and (6) risk, referring to economic sustainability;

- (7) internal social sustainability, which takes the wellbeing of the farmer and his family as a focal point, (8) external social sustainability, which is related to the expectations of the society vis à vis agriculture and (9) disposable income, referring to social sustainability.

- It is clear that integrating these diverse principles and themes into a farm's management will require a considerable amount of entrepreneurship of the (future) farmers. Therefore, we added entrepreneurship (10) as an additional theme for the sustainability monitor.

\subsection{The indicators}

Table I summarizes the indicators we designed for each of the ten relevant sustainability themes. For each indicator, a concise definition and methodological choices concerning the indicators' design, data use, scoring method and weight are shown. The ten major sustainability themes accomplish level 1 of the monitoring tool. This level applies to any agricultural sector. Because some of these themes are very broad, they were further subdivided (level 2). The themes and indicators at level 2 and level 3 specifically relate to the dairy sector, e.g. the indicators for animal health and welfare, although many of them are also valid for other agricultural sectors.

As stated before, some indicators receive a specific weight when they are considered more or less important than other indicators. This was the case for the indicators designed to evaluate a farm's 'productivity and efficiency' and for the indicators of 'soil quality'. For 'productivity and efficiency', we assigned half of the theme's weight to 'efficiency' and the other half to the partial productivity indicators, of which in turn 'labor productivity' takes $54 \%$, 'capital productivity' $21 \%$ and 'land productivity' $25 \%$. These weights take into account production economic aspects, since they are based on the estimation of a Cobb-Douglas production function (Coelli et al., 1998) using a sample of dairy farms. Since the soil organic matter (OM) content highly influences the chemical, physical and biological quality of a soil (a.o. Davidson, 2000), it is considered to be a key indicator of soil quality. We therefore assigned 'OM content' half of the total weight of the theme 'soil quality'.

As an example, we illustrate the applied methodology of indicator construction, data use, scoring and weighting, for the 'energy use efficiency' indicator of the case-study farm:

- Indicator design: the choice of 'energy use efficiency' as a relevant indicator for 'energy use' and its calculation method were based on scientific knowledge retrieved from the literature. A detailed description of the indicator and its calculation method is provided by Meul et al. (2007a).

- Data use: the indicator calculation is based on quantitative data retrieved from the financial farm account. The used amounts of direct farm inputs (diesel fuel, electricity and natural gas) and indirect farm inputs (mineral fertilizers, seeds, pesticides, concentrates, forages and machines) were converted into energy values using literature-based conversion factors.

- Indicator calculation and scoring: Table II shows the calculation of the annual total energy use of the case-study farm in 2003. Considering a milk production of $15605 \mathrm{~L}$ $\mathrm{ha}^{-1}$ this resulted in an energy use efficiency of $29 \mathrm{~L}$ milk $100 \mathrm{MJ}^{-1}$. We defined benchmarks based on the indicator values of a reference group of comparable farms, in this case the specialized dairy farm data of the Flemish Farm Accountancy Data Network (FADN). The 10\% best-performing farms delimited the 100 score, the $10 \%$ lowest-performing farms the 0 score. The indicator value of the case-study farm was transferred into a score of 88 , as shown in Figure 1.

- Indicator weighting: since there was no explicit evidence that the indicator 'energy use efficiency' is more or less important than the 'renewable energy use' to evaluate a farm's energy use, we gave both indicators the same weight. The weights in Table I take into account the assumption that the four aspects of the use of inputs (pesticides, energy, water and nutrients) are considered equally important.

For detailed information concerning the selection, design and calculation of other indicators in Table I, we refer to the publications of Nevens et al. (2006), Meul et al. (2007b), Goossens et al. (2007) and Steunpunt Duurzame Landbouw (2006).

\subsection{The monitoring instrument: MOTIFS}

We aggregated the scores of the different sustainability indicators into an integrated tool, which we named MOTIFS: MOnitoring Tool for Integrated Farm Sustainability (Fig. 2). 


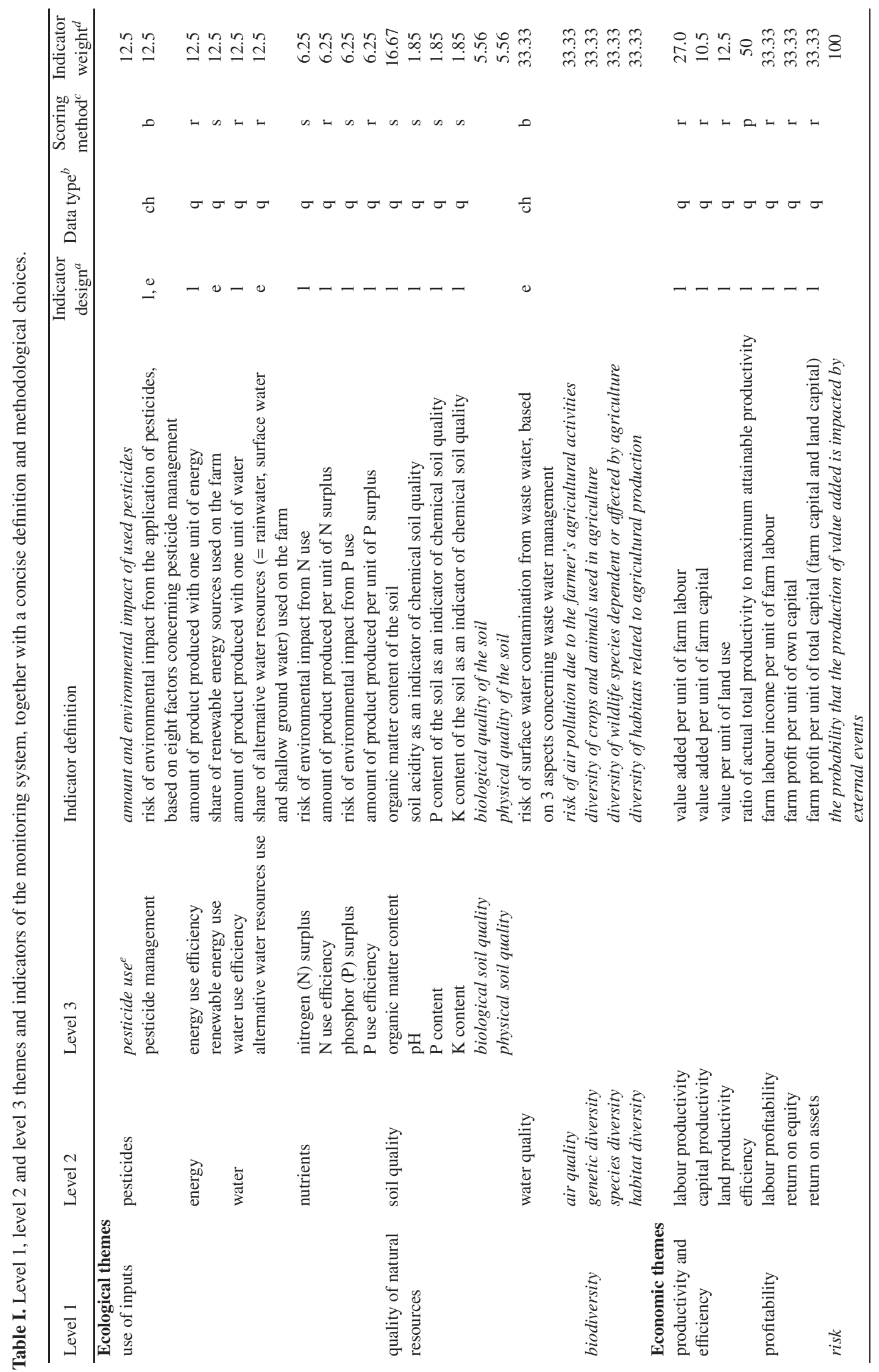




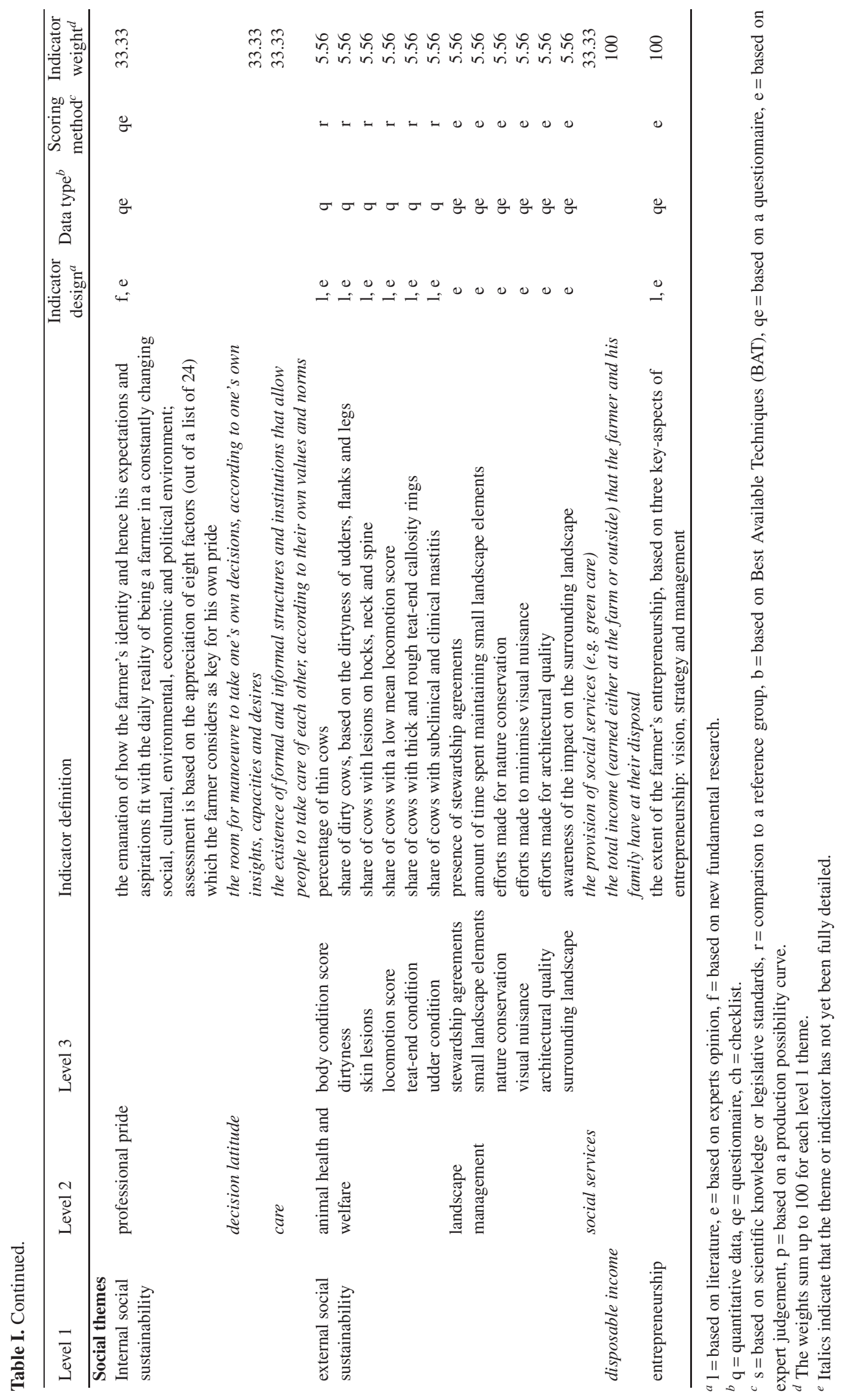




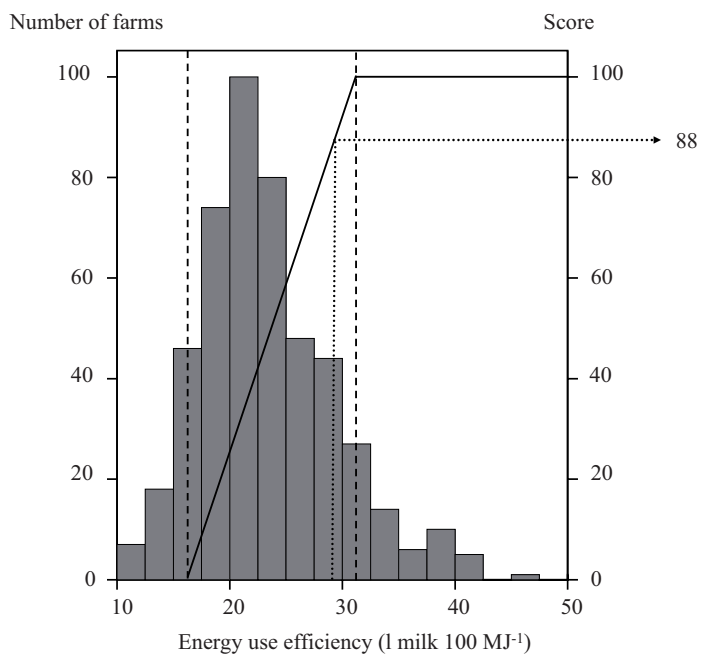

Figure 1. Histogram of the energy-use efficiencies of the dairy farms of the Flemish Farm Accountancy Data Network (FADN) - dataentries of the years 1989, 1990, 2000 and 2001. The $10 \%$ best farms delimit the 100 score, the $10 \%$ worst farms the 0 score; the indicator value of the case-study farm (291 milk/100 MJ) is linearly transferred into a score of 88 .

Table II. Annual total energy use of the case-study dairy farm, data of the year 2003 .

\begin{tabular}{lr}
\hline Energy input & MJ/ha \\
\hline Direct energy input & \\
diesel & 7529 \\
lubricants & 666 \\
electricity & 4148 \\
other sources & 1753 \\
total & 14096 \\
Indirect energy input & \\
mineral fertilizer & 5987 \\
seeds & 457 \\
pesticides & 393 \\
machinery & 2221 \\
concentrates & 30037 \\
forages & $0^{*}$ \\
total & 39095 \\
Total energy input & 53191 \\
\hline purchased.
\end{tabular}

* No forages were purchased.

MOTIFS allows for an immediate visual interpretation of a farm's sustainability for each of the ten major themes. The more a graph segment is filled with color, the more a farm is considered sustainable for that specific theme.

The sustainability monitoring of the case-study dairy farm is visualized in the radar graphs of Figure 3. The top graph (a) shows the overall sustainability of the farm, i.e. at the level of the ten major themes (level 1). The themes that have not yet been measured are left blank. Starting from this level 1 graph, the farmer can zoom in on each of the three sustainability dimensions. The scores of their relevant themes and indicators are presented in an economic (b), an ecological (c) and a social (d) level 2 graph in Figure 3. At level 3, the indicator scores are visualized for a specific theme. In our case study, level 3 graphs were made for the use of inputs (e), quality of natural resources (f) and external social sustainability (g).

\subsection{Overall discussion}

With the applied methodology, we tried to answer some of the comments on existing monitoring tools, as formulated in the introduction part of this article: through the applied sequence of methodological steps - from vision over themes to indicators - we explained in detail how and why the considered themes and indicators were selected and we avoided using indicators that are not relevant to the problem at hand, or that are selected based on the availability of data rather than on scientific soundness and relevance. MOTIFS is also founded on the equality of the economic, ecological and social sustainability dimensions, and this equality is inherently built into the system.

Stakeholder participation and expert consulting played an important part in the development of MOTIFS. This approach has been found very successful for developing sustainability indicators (van Calker et al., 2005). Moreover, discussions among stakeholders - based on scientific information - may themselves contribute to the development of sustainable farming systems (Rossing et al., 1997). According to Oels (2003), dialogue between stakeholders and actors at all levels is essential to translate shared understandings and interpretations into collective action on sustainable development.

We encourage the application of MOTIFS on farms in practice, even though not all indicators have been worked out yet in detail, for a number of reasons:

- Even though some of them have not been worked out yet at farm level, by explicitly including these themes and indicators in the tool (Tab. I, in italics), it is emphasized that the list of indicators that can already be used is not limitative, and that the result is not yet a complete monitoring of a farm's overall sustainability. Moreover, when the farmer is aware of some data gaps to calculate indicators, he might be stimulated to collect these farm data that are needed for the sustainability evaluation.

- Application of the monitoring tool in practice is necessary to be able to perform a sound end-use validation.

- Since 'sustainability' is not a static concept, but characterizes a constant evolution, a monitoring tool to evaluate sustainability will never be 'finished'. Themes, indicators and benchmarks - and consequently also the monitoring tool - will continuously be subjected to change. We anticipated that possible change by developing a flexible tool in which it is easy to add or remove themes and indicators, or to change benchmarks, but that also fits well within a sound theoretical frame of vision - principles - themes indicators.

MOTIFS could be a promising integrated tool to guide (dairy) farmers' management towards a higher level of sustainability. The visual integration of relevant themes of ecological, economic and social sustainability aspects and sustainable 


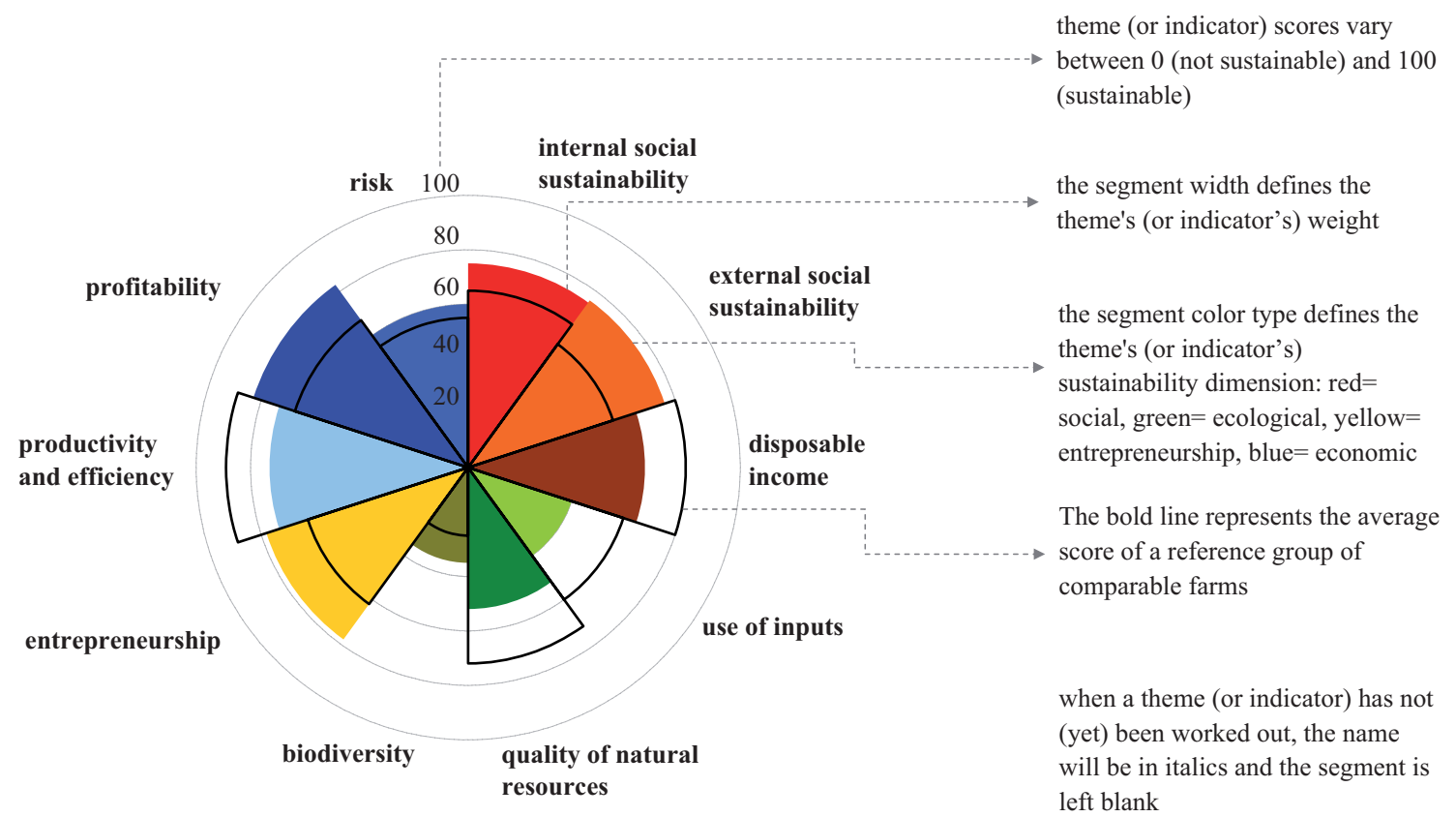

Figure 2. MOTIFS, level 1 graph and instructions on the reading and interpretation.

entrepreneurship allows an immediate and integrated interpretation of a farm's overall sustainability level and gives an overview of the farm's strengths and weaknesses. Taking into account the pre-defined indicator quality criteria of causality, sensitivity, solidness, comprehensibility and the use of benchmarks, we developed a set of indicators that can be used as a complete and relevant decision-aid tool for farmers. Apart from that, the specific attention we gave to aspects of communication and user-friendliness resulted in a monitoring tool that seems particularly interesting for use in discussion groups of farmers to mutually compare results and exchange knowledge and expertise. Moreover, by using the monitoring tool to compare farm performances of an individual farm over time, the farmer can follow up whether management actions actually result in the desired effect. This could make MOTIFS a useful management tool.

Introducing the tool to farmers appears realistic and promising, since farmers' organizations have already shown interest in applying the tool in practice on Flemish farms. For the moment, MOTIFS is being used on 20 Flemish dairy farms participating in a Leader+ project (European Commission, 2007). During the period 2006-2008, a project leader visits the farmers, collects farm data, calculates indicators and makes radar graphs with the results of each farm. Those results are then presented in a discussion group where the farmers can compare the weak and strong aspects of their farms and discuss possible actions to be taken. This practical application functions as an end-use validation of MOTIFS, since feedback is received from the farmers on the practical use, data collection, invested time and costs, allowing an optimization of the indicators and of the tool as a whole.

However, work should still be done on some important unfinished aspects of MOTIFS. First of all, all themes and indi- cators (as summarized in Tab. I) should be worked out in detail. Secondly, to translate the theoretical outcome of MOTIFS into agricultural practice, management advice and guidance is needed. To a certain level, the farmers can develop appropriate management strategies by themselves, considering their own priorities and conditions and based on the provided indicator descriptions or calculation methods. However, to enhance a successful implementation and hence guide farmers' actions towards a higher level of sustainability, case- and site-specific advice should be provided (von Wirén-Lehr, 2001). This could possibly be fulfilled by farm advisors, who are highly qualified to discuss the different sustainability aspects in confidence with the farmers and to provide additional information and advice that is essential to decide on appropriate measures and to take actions.

Finally, although we believe that MOTIFS can guide farmers to take the proper actions towards more sustainable agricultural systems, we think that in truly sustainable systems, unsustainable situations or impacts should not only be reduced, but radically eliminated. Therefore, totally new production systems should be considered and/or designed. This is a long-term process. In such a context of transition towards future (agricultural) production, optimization of current systems is a first step to translate 'sustainability' into concrete actions. MOTIFS is considered a suitable guide in this optimization effort, but one should be aware of the potential danger to lock even optimized systems into suboptimal future development paths.

\section{CONCLUSION}

In this article we proposed a methodological framework for developing MOTIFS, a monitoring tool to guide Flemish 


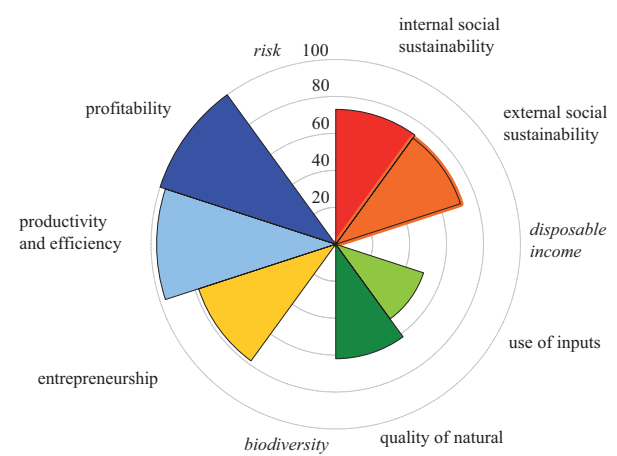

(a)

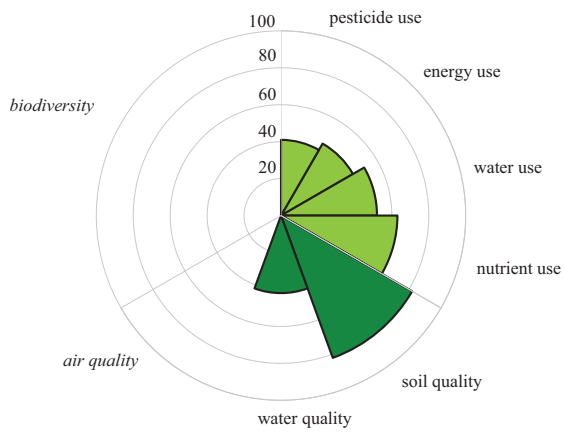

(c)

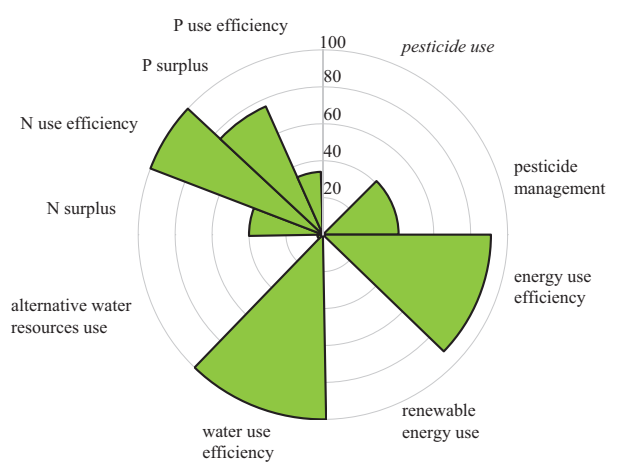

(e)

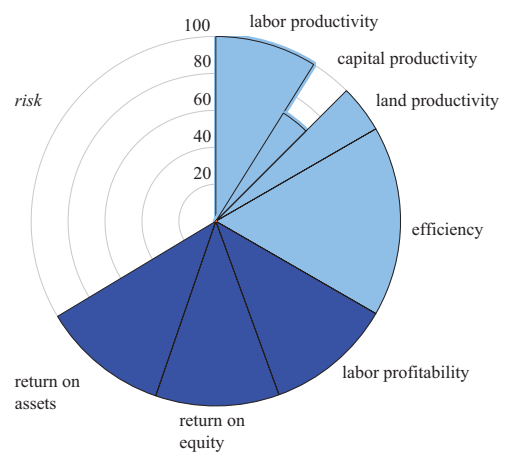

(b)

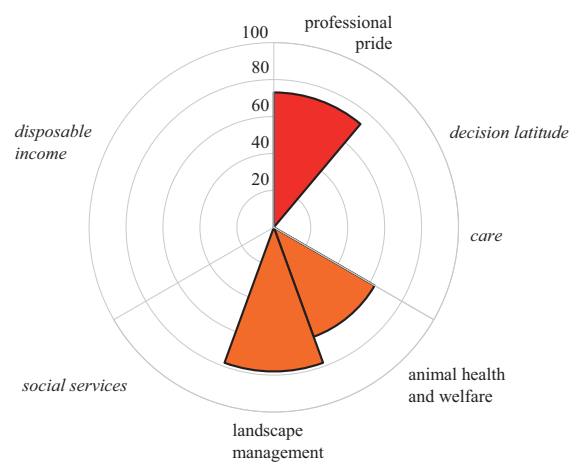

(d)

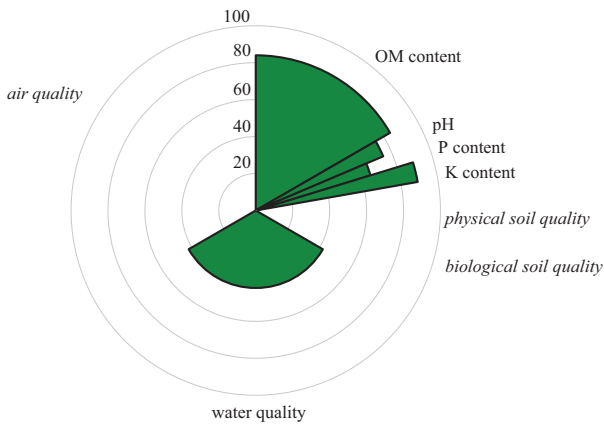

(f)

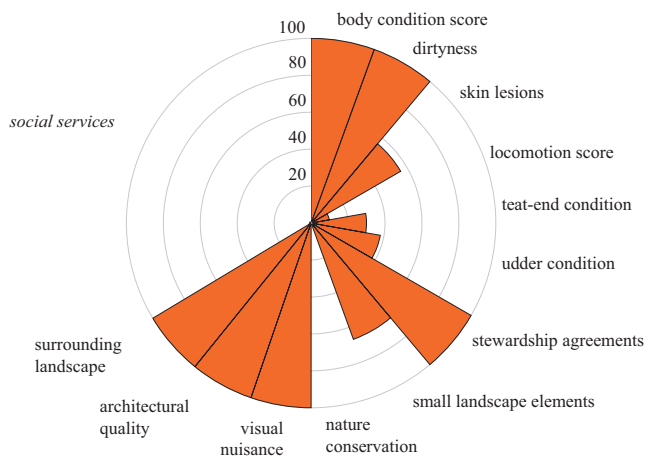

(g)

Figure 3. Results of the sustainability monitoring of the case-study dairy farm: level 1 (a) gives an overview of the farm's integrated sustainability, level 2 gives an overview of the sustainability of the economic (b), ecological (c) and social (d) dimensions and level 3 shows the indicator scores for the use of inputs (e), quality of natural resources (f) and external social sustainability (g). 
(dairy) farms towards a higher sustainability level, and we illustrated its practical use on a specific Flemish dairy farm as a case study. The methodology consisted of four successive steps:

- translating the major principles of a supported vision of sustainable Flemish agriculture into concrete and relevant themes;

- designing indicators to monitor progress towards sustainability for each of those themes;

- aggregating the indicators into an integrated farm sustainability monitoring tool;

- applying the monitoring tool on a practical farm, as a first end-use validation.

Stakeholder participation and expert consulting played an important part in each of these methodological steps. As a result, we developed a user-friendly and strongly communicative instrument to measure progress towards integrated sustainable dairy farming systems. MOTIFS is founded on the equality of the economic, ecological and social sustainability dimensions, and this equality is inherently built into the system. The tool fits within a well-founded methodological framework and is based on a set of relevant indicators. Through the applied methodology, we avoided using indicators that are not relevant to the problem at hand, or that are selected based on the availability of data rather than on scientific soundness and relevance. In our opinion, the end-use validation of the tool is of critical importance to its optimization and continuous improvement. For that reason we encourage its application on as many practical Flemish farms as possible, even though at this stage not all indicators have been worked out in detail.

\section{REFERENCES}

Astleithner F., Hamedinger A. (2003) The analysis of sustainability indicators as socially constructed policy instruments: benefits and challenges of 'interactive research', Local Environ. 8, 627-640.

Bell S., Morse S. (1999) Sustainability indicators: measuring the immeasurable? Earthscan, London.

Bell S., Morse S. (2003) Measuring sustainability: learning from doing, Earthscan, London.

Bockstaller C., Girardin P. (2003) How to validate environmental indicators, Agr. Syst. 76, 639-653.

Bockstaller C., Girardin P., van der Werf H.M.G. (1997) Use of agroecological indicators for the evaluation of farming systems, Eur. J. Agron. 7, 261-270.

Bossel H. (1999) Indicators for sustainable development: theory, method, applications. A report to the Balaton Group, International Institute for Sustainable Development, Winnipeg, Canada.

Cloquell-Ballester V-A., Colquell-Ballester V-A., Monterde-Díaz R., Santamarina-Siurana M.-C. (2006) Indicator validation for the improvement of environmental and social impact quantitative assessment, Environ. Impact Assessment Rev. 26, 79-105.

Coelli T.J., Rao D.S.P., Battese G.E. (1998) An introduction to efficiency and productivity analysis, Kluwer Academic Publisher, Boston, USA.

Cousins C. (1999) Social exclusion in Europe / Paradigms of social disadvantage in Germany, Spain, Sweden and the United Kingdom, Policy Politics 26, 127-146.
Davidson D.A. (2000) Soil quality assessment: recent advances and controversies, Prog. Environ. Sci. 2, 342-350.

Dessein J., Nevens F. (2007) "I'm sad to be glad", An analysis of farmer's pride in Flanders, Sociologia Ruralis 47, 273-292.

European Commission (2007) Leader+ interactive, accessed on: http://ec.europa.eu/ agriculture/rur/leaderplus/index_en.htm

Farrell A., Hart M. (1998) What does sustainability really mean? The search for useful indicators, Environment 40, 4-9.

Figge F., Hahn T. (2004) Value-oriented impact assessment: the economics of a new approach to impact assessment, J. Environ. Planning Manage. 6, 921-941.

Geels F. (2005) Technological transitions and system innovations, Edward Elgar, UK.

Girardin P., Bockstaller C., van der Werf H. (2000) Assessment of potential impacts of Agricultural practices on the environment: the AGRO*ECO method, Environ. Impact Assessment Rev. 20, 227239.

Gomez A.A., Swete Kelly D.E., Syers J.K., Coughlan K.J. (1996) Measuring sustainability of agricultural systems at the farm level, Methods for assessing soil quality, SSSA Special Publication 49, 401-409.

Goossens X., Sobry L., Ödberg F., Tuyttens F., Maes D., De Smet S., Nevens F., Opsomer G., Lommelen F., Geers R. (2007) A population based on-farm evaluation protocol for comparing the welfare of pigs between farms, Animal Welfare, in press.

Hardi P., Zdan T. (1997) Assessing sustainable development: Principles in practice, International Institute for Sustainable Development, Winnipeg, Canada.

Jollands N., Lermit J., Patterson M. (2004) Aggregate eco-efficiency indices for New- Zealand - a principal components analysis, J. Environ. Manag. 73, 297-305.

Lewis K.A., Bardon K.S. (1998) A computer-based informal environmental management system for agriculture, Environ. Modell. Softw. 13, 123-137.

Meul M., Nevens F., Reheul D., Hofman G. (2007a) Energy use efficiency of specialised dairy, arable and pig farms in Flanders, Agr. Ecosyst. Environ. 119, 135-144.

Meul M., Nevens F., Verbruggen I., Reheul D., Hofman G. (2007b) Operationalising eco-efficiency in agriculture: the example of specialised dairy farms in Flanders, Prog. Ind. Ecol. 4, 41-53.

Nevens F., Dessein J., Mathijs E., Sturtewagen G., Hongenaert M. (2005) On tomorrow's grounds. Development of a vision on Flemish agriculture in 2030, European Roundtable on Sustainable Consumption and Production - erScp 10: Europe's Transition: Lean and Clean?! October 5-7 2005, Antwerp, Belgium.

Nevens F., Dessein J., Meul M., Rogge E., Verbruggen I., Mulier A., Van Passel S., Lepoutre J., Hongenaert M. (2007) On tomorrow's grounds; development of a vision on Flemish agriculture in 2030, J. Cleaner Prod. (in press).

Nevens F., Verbruggen I., Reheul D., Hofman G. (2006) Farm gate nitrogen surpluses and nitrogen use efficiency of specialized dairy farms in Flanders: evolution and future goals, Agr. Syst. 88, 142-155.

Oels A. (2003) Evaluating stakeholder participation in the transition to sustainable development. Methodology, case studies, policy implications, LIT Verslag, Münster.

Rigby D., Woodhouse P., Young T., Burton M. (2001) Constructing a farm level indicator of sustainable agricultural practice, Ecol. Econ. 39, 463-478.

Rossing W.A.H., Meynard J.M., van Ittersum M.K. (1997) Modelbased explorations to support development of sustainable farming 
systems: case-studies from France and the Netherlands, Eur. J. Agron. 7, 271-283.

Rotmans J. (2003) Transitiemanagement, sleutel voor een duurzame samenleving, Koninklijke Van Gorcum, Assen, The Netherlands.

Steunpunt Duurzame Landbouw (2006) Erven van de toekomst. Over duurzame landbouw in Vlaanderen, Steunpunt Duurzame Landbouw, Gontrode, Belgium.

Taylor D.C., Abidin Mohamed Z., Nasir Shamsudin M., Ghazali Mohayidin M, Chiew E.F.C. (1993) Creating a farmer sustainability index: a Malaysian case study, Am. J. Alternative Agr. 8, 175-184.

Thompson Klein J., Grossenbacher-Mansuy W., Häberli R., Bill A., Scholz R.W., Welti M. (Eds.) (2001) Transdisciplinarity: joint problem solving among science, technology and society. An effective way for managing complexity, Birkhäuser, Berlin.

van Calker K.J., Berentsen P.B.M., Giesen G.W.J., Huirne R.B.M. (2005) Identifying and ranking attributes that determine sustainability in Dutch dairy farming, Agr. Human Values 22, 53-63. van der Werf H.M.G., Petit J. (2002) Evaluation of the environmental impact of agriculture at the farm level: a comparison and analysis of 12 indicator-based methods, Agr. Ecosyst. Environ. 93, 131-145.

Van Passel S., Lauwers L., Van Huylenbroeck G. (2006) Factors of farm performance: an empirical analysis of structural and managerial characteristics, in: Mann S. (Ed.), Causes and impacts of agricultural structures Nova Science Publishers Inc., New York, pp. 3-22.

Van Passel S., Nevens F., Mathijs E., Van Huylenbroeck G. (2007) Measuring farm sustainability and explaining differences in sustainable efficiency, Ecol. Econ. 62, 149-161.

Von Wirén-Lehr S. (2001) Sustainability in agriculture - an evaluation of principal goal-oriented concepts to close the gap between theory and practice, Agr. Ecosyst. Environ. 84, 115-129.

WBCSD (2000) Eco-efficiency. Creating more value with less impact, World Business Council for Sustainable Development, North Yorkshire.

WCED (World Commission on Environment and Development) (1987) Our Common Future, Oxford University Press, UK. 